\title{
Melanotic oncocytic metaplasia of the nasopharynx as a benign mimicker of malignant melanoma: a case report
}

\author{
Takeshi Kondo ${ }^{1 *}$, Kiyoshi Mori', Shiori Oka², Setsuko Morinaka ${ }^{3}$
}

\begin{abstract}
Introduction: Melanotic variant of oncocytic metaplasia of the nasopharynx is an extremely rare condition.

Case report: A 73-year-old Japanese man presented with nasal congestion and chill. Nasoscopic examination revealed multiple black nodules around the bilateral torus tubarius. The nodules were biopsied to determine the histology. The clinical differential diagnosis was malignant melanoma or hemangioma. Microscopically, there were oncocytic plump cells with abundant brown pigmented granules showing glandular pattern. No significant atypia was found. The pigment was positive for Fontana-Masson staining, and negative for Berlin blue staining, showing that it was melanin pigment. Immunohistochemically, S100-positive HMB45-negative dendritic cells were also found.
\end{abstract}

Conclusion: Such a pigmented variant of benign oncocytic lesion is very rare, and only 15 cases have been reported in the English literature. As a benign mimicker of malignant melanoma, melanocytic oncocytic metaplasia should be always taken into consideration in the clinical setting.

\section{Background}

In 1995, Shek et al. originally reported two cases of melanotic oncocytic metaplasia of the nasopharynx [1]. Since then, only 13 cases have been reported in English literature [2-5]. We present here an additional case (the 16th case in English literature) of melanotic oncocytic metaplasia in the nasopharynx.

\section{Case presentation}

A 73-year-old Japanese man presented with the feeling of nasal congestion (obstruction) and chill. His past medical history was unremarkable and he was a nonsmoker. During nasoscopic examination multiple black nodules, measuring several millimeters, were discovered around the bilateral torus tubarius (Fig 1AB). While the patient was under followup at Oka ENT clinic for 4 months, the lesion grew slightly larger. The patient was then referred to Kobe Japanpost Hospital. No obstruction of the Eustachian tube opening was observed. His external auditory canal and tympanic membrane were

\footnotetext{
* Correspondence: kondo@med.kobe-u.ac.jp
'Division of Pathology, Kobe University Graduate School of Medicine, Kobe,

*Correspondence: kondo@med.kobe-u.ac.jp
'Division of Pathology, Kobe University Graduate School of Medicine, Kobe, Japan
}

(c) 2010 Kondo et al; licensee BioMed Central Ltd. This is an Open Access article distributed under the terms of the Creative Commons Attribution License (http://creativecommons.org/licenses/by/2.0), which permits unrestricted use, distribution, and reproduction in any medium, provided the original work is properly cited. ynx revealed no abnormality. The clinical impression was that of malignant melanoma or hemangioma. This lesion was biopsied and histological examination was performed. Microscopically, the nodule was composed of plump epithelial cells with diffuse oncocytic metaplasia. These oncocytic cells had uniformly abundant eosinophilic granular cytoplasm on hematoxylin and eosin staining, and were arranged in a tubular or glandular pattern (Fig. 1C). Scattered brown pigments were also noted in the cytoplasm of oncocytic cells (Fig. 1C). Fontana-Masson stain confirmed that these pigments were melanin granules (not shown) and staining for hemosiderin (Berlin blue stain) was negative (not shown). By immunohistochemistry, S100-positive HMB45-negative dendritic cells were scattered in the lesion (Fig. 1D, arrows). Although oncocytic metaplasia occurring in melanoma has been reported [6], this lesion was easily differentiated from melanoma because of the absence of malignant component. Based on the above findings, the lesion was diagnosed as melanotic oncocytic metaplasia. The patient is doing well and the follow-up has been uneventful. 

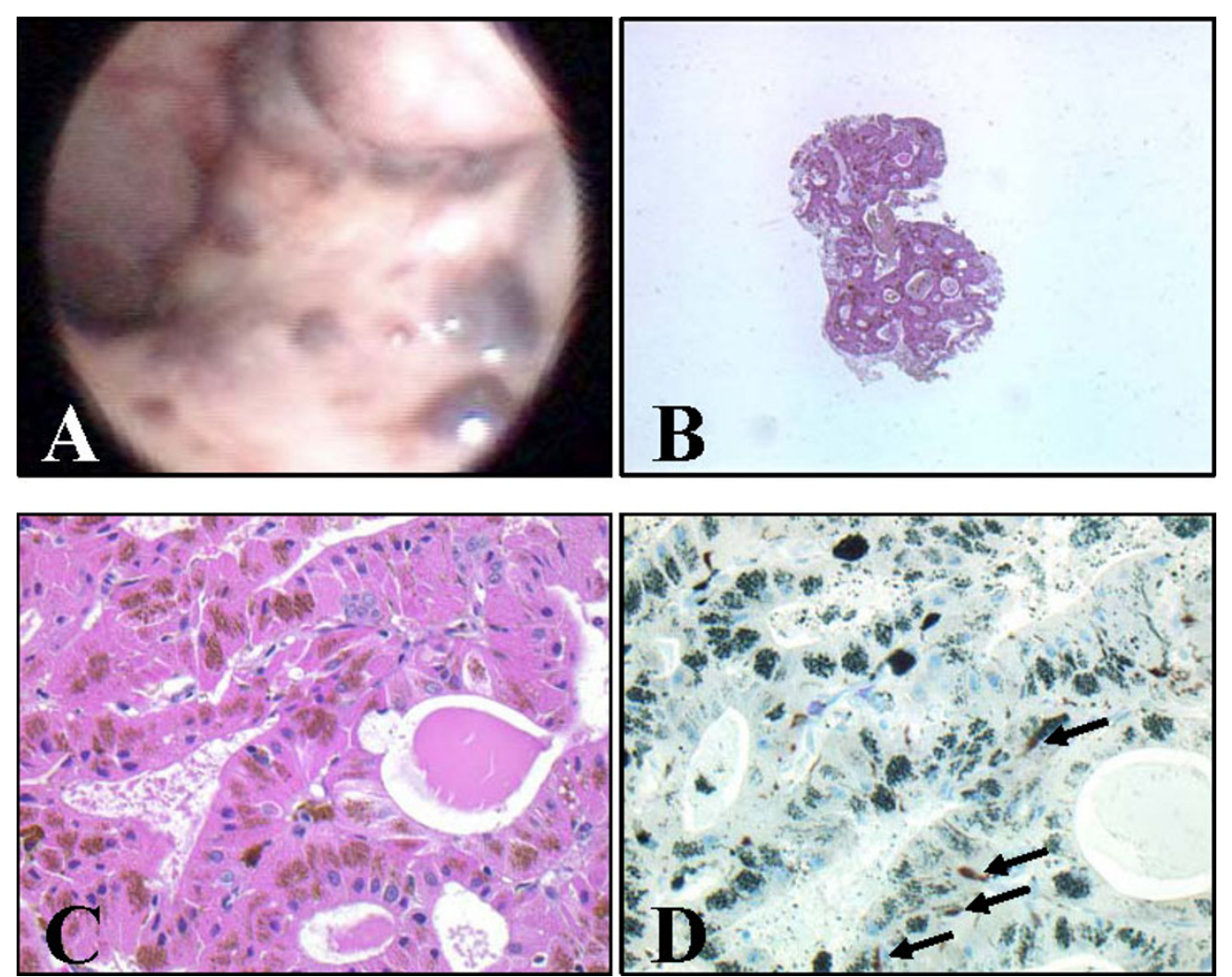

Figure 1 Macroscopic and microscopic findings of the lesion. A: Endonasal view of the nasopharynx, with multiple melanotic lesions around the Eustachian tuber (left side). B: Microscopic findings of the lesion (hematoxylin and eosin stain, low magnification). C: Microscopic findings of the lesion (hematoxylin and eosin stain, high magnification). Plump epithelial cells with eosinophilic cytoplasm and many brown pigmented granules are arranged in a tubular pattern. D: Immunohistochemical findings of the lesion (S-100). S100-positive HMB45-negative dendritic cells were scattered in the lesion (arrows). By counterstaining with Giemsa stain, melanin pigment showed heterochromasia (green).

\section{Discussion}

Oncocytic cells are large epithelial cells with eosinophilic, granular cytoplasm. Oncocytic metaplasia (change) is most frequently encountered in certain epithelial organs, such as the salivary gland, the lacrimal gland, the parathyroid gland, the thyroid gland, the pulmonary tree, and the kidney [4]. Oncocytes are not found in these organs of younger persons. The frequency of this oncocytic metaplastic change increases with age, its exact significance and biological function are, however, still unknown [2]. It is generally believed that the oncocyte represents a form of cellular degeneration [7]. Because oncocytes are discovered predominantly in elderly persons, they have undergone cytoplasmic change and are considered to be involved in an aging process [4].

Oncocytic change in the upper respiratory tract is an uncommon finding and melanotic variant of oncocytic metaplasia of the nasopharynx is an extremely rare condition. To our knowledge, 15 cases have been reported in the literature and our case is the 16th case.

The lesion may be single or multiple. Most of the lesions are asymptomatic and tend to be incidentally discovered during examination of the nasopharynx. Some of these lesions may occasionally produce symptoms. When the mucosa around the opening of Eustachian tube is affected, ear or nose symptoms may occur. Eustachian tube dysfunction can be caused when the tissue edema accompanying the lesions impairs the tube function. In this case, the feeling of nasal congestion (obstruction) may be due to Eustachian tube dysfunction, and the chill may be coincidental.

All reported cases including our case are elderly males in their sixties or seventies. The lesion may be misinterpreted clinically as early nasopharyngeal carcinoma, nevus, or malignant melanoma. The origin of the melanin pigment is in question. The exact nature of melanin-containing oncocytes in the nasopharynx awaits further clarification.

\section{Conclusion}

In conclusion, we report the 16th case of melanin-containing oncocytic metaplasia of the nasopharynx. As a benign mimicker of malignant melanoma, melanocytic oncocytic metaplasia should be always taken into consideration in the clinical setting. 


\section{Consent}

Written informed consent was obtained from the patient for publication of this case report and accompanying images. A copy of the written consent is available for review by the Editor-in-Chief of this journal.

\section{Acknowledgements}

We thank Miki Zenigami-Yamazaki, Noriko Sakamoto, and Shuichi Matsuda at Kobe University for their excellent technical assistance.

\section{Author details}

'Division of Pathology, Kobe University Graduate School of Medicine, Kobe, Japan. ${ }^{2}$ Oka ENT Clinic, Kobe, Japan. ${ }^{3}$ Department of Otorhinolaryngology,

Kobe Japanpost Hospital, Kobe, Japan.

\section{Authors' contributions}

TK and KM performed histological examination and analyzed the case. TK was a major contributor in writing the manuscript. SO and SM treated the patient and provided clinical images. All authors read and approved the final manuscript.

\section{Competing interests}

The authors declare that they have no competing interests.

Received: 24 October 2009

Accepted: 14 January 2010 Published: 14 January 2010

\section{References}

1. Shek TW, Luk IS, Nicholls JM, Fok KO: Melanotic oncocytic metaplasia of the nasopharynx. Histopathology 1995, 26:273-275.

2. Xue WC, Hui YZ: Melanotic oncocytic metaplasia of the nasopharynx. Histopathology 2001, 35:481-482.

3. Sakaki M, Shek TW, Hirokawa M, Kashima K, Daa T, Gamachi A, Sano T: Melanotic oncocytic metaplasia of the nasopharynx: a report of seven cases and review of the literature. Virchows Arch 2004, 444:345-349.

4. Takano K, Sato J, Shirasaki H, Yamazaki N, Hoki K, Himi T: Melanin pigmented oncocytic metaplasia of the nasopharynx. Auris Nasus Larynx 2004, 31:161-163.

5. Liao CT, Kuo TT: Images in pathology. Melanotic oncocytic metaplasia of the nasopharynx. Int J Surg Pathol 2005, 13:279.

6. Jih DM, Morgan MB, Bass J, Tuthill R, Somach SC: Oncocytic metaplasia occurring in melanoma. Semin Cutan Med Surg 2004, 23:73-79.

7. Lim CT: Oncocytic metaplasia of the nasopharynx. Otorhinolaryngol Head Neck Surg 1998, 118:419.

doi:10.1186/1746-1596-5-5

Cite this article as: Kondo et al:: Melanotic oncocytic metaplasia of the nasopharynx as a benign mimicker of malignant melanoma: a case report. Diagnostic Pathology 2010 5:5.

Publish with Bio Med Central and every
scientist can read your work free of charge

"BioMed Central will be the most significant development for disseminating the results of biomedical research in our lifetime. "

Sir Paul Nurse, Cancer Research UK

Your research papers will be:

- available free of charge to the entire biomedical community

- peer reviewed and published immediately upon acceptance

- cited in PubMed and archived on PubMed Central

- yours - you keep the copyright 